\title{
The ionospheric behavior in conjugate hemispheres during the 3 October 2005 solar eclipse
}

\author{
H. Le ${ }^{1,2}$, L. Liu ${ }^{1}$, X. Yue ${ }^{1}$, and W. Wan ${ }^{1}$ \\ ${ }^{1}$ Beijing National Observatory of Space Environment, Institute of Geology and Geophysics, Chinese Academy of Sciences, \\ Beijing 100029, China \\ ${ }^{2}$ Graduate School of the Chinese Academy of Sciences, Beijing 100049, China
}

Received: 22 September 2008 - Revised: 12 December 2008 - Accepted: 12 December 2008 - Published: 9 January 2009

\begin{abstract}
We investigate the ionospheric behavior in conjugate hemispheres during the 3 October 2005 solar eclipse, on the basis of observations of electron temperature $\left(T_{e}\right)$ from the Defense Meteorological Satellites Program (DMSP) spacecraft, F2 layer critical frequency $(f o \mathrm{~F} 2)$ and $\mathrm{F} 2$ layer peak height $(h m \mathrm{~F} 2)$ at the Grahamstown ionosonde station, and total electron content (TEC) from the Global Positioning System (GPS) station SUTH. The observations show that when the eclipse occurred in the Northern Hemisphere, there was a decrease in $T_{e}$, an increase in $f o \mathrm{~F} 2$ and TEC, and an uprising in $h m \mathrm{~F} 2$ in its conjugate region compared with their reference values. We also simulated the ionosphere behavior during this eclipse using a mid- and low-latitude ionospheric model. The simulations agree well with the observations. Because of the eclipse effect, there are far fewer photoelectrons travelling along the magnetic field lines from the eclipse region to the conjugate region, resulting in reduced photoelectron heating in the conjugate hemisphere which causes a drop in electron temperature and subsequent disturbances in the region.
\end{abstract}

Keywords. Ionosphere (Ionospheric disturbances; Midlatitude ionosphere; Modeling and forecasting)

\section{Introduction}

The ionospheric responses to a solar eclipse have been studied extensively with various methods, such as the Faraday rotation measurement, ionosonde network, incoherent scatter radar (ISR), Global Positioning System (GPS), and satellite measurements (e.g., Salah et al., 1986; Tsai and Liu,

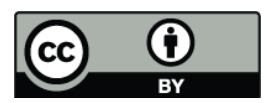

Correspondence to: L. Liu

(liul@mail.iggcas.ac.cn)
1999; Afraimovich et al., 1998; Davis et al., 2000) as well as theoretical modelling (Stubbe, 1970; Müller-Wodarg et al., 1998; Boitman et al., 1999; Le et al., 2008a). These studies have shown that there is an almost consistent behavior at low altitudes where there are distinct depletions in electron concentration and electron temperature during solar eclipses. The F2 region behavior may be quite different accompanied with various amplitudes of decrease or even a small increase in the electron concentration. Combining the measurements and four controlled case simulations, Le et al. (2008b) found that most of the observed differences in the behavior of the peak electron density of the $\mathrm{F} 2$ layer $(\mathrm{Nm} \mathrm{F} 2)$ during eclipses can be attributed to the differences in $\mathrm{O}^{+}$loss rates brought about by the background differences in the neutral molecular densities. Despite many studies on the eclipse effects of the ionosphere over the eclipse region, there are still rarely studies on the ionospheric disturbances in the magnetically conjugate regions.

An annular eclipse occurred over Europe in the morning hours of 3 October 2005. Based on the vertical incidence sounding, High-frequency Doppler, and ionosonde measurements in Europe, Jakowski et al. (2008) investigated the ionospheric behavior during the annular eclipse and obtained some results such as the reduction in electron density in the E, F1, and F2 layer, the generation of AGW, and the increase in equivalent slab thickness. Different from Jakowski et al. (2008), in this paper, we will investigate the ionospheric disturbances in the Southern Hemisphere when the eclipse occurred in the Northern Hemisphere through various measurements including electron temperature from the DMSP spacecraft, F2 layer critical frequency and F2 layer peak height from an ionosonde measurement, and total electron content from GPS measurements. Furthermore, we carry out a modeling study of the solar eclipse effects of the ionosphere at conjugate regions by using a theoretical ionosphere model and compare the simulations with the observations. 

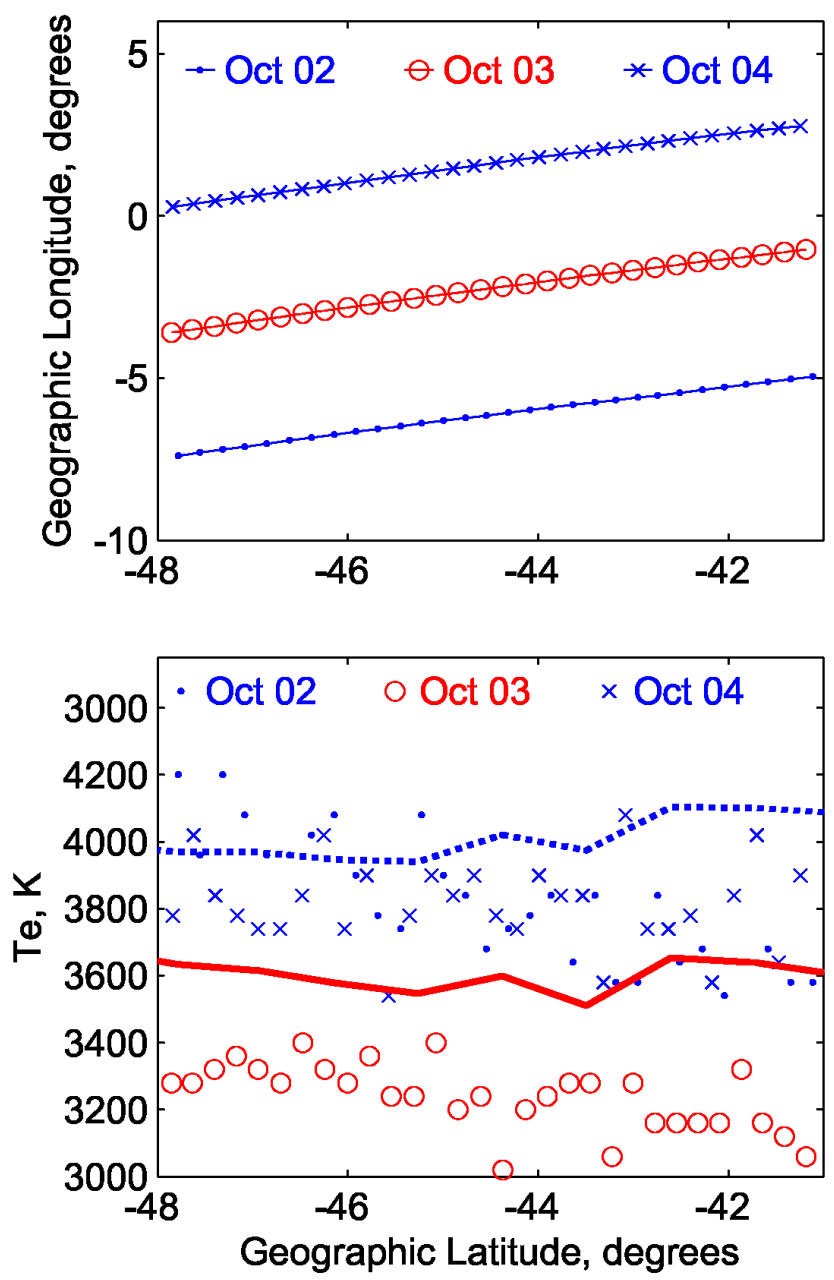

Fig. 1. Top panel: the spatial locations of the F15 satellite at 08:3108:33 UT on 2 October, 08:15-08:17 UT on 3 October, and 08:00 08:02 UT on 4 October. Bottom panel: the measured values of electron temperature at the corresponding locations and times. The simulated results on the eclipse day (solid line) and the control day (dotted line) are also plotted in the bottom panel.

\section{Data analyses}

DMSP spacecraft are launched into a near polar, Sun synchronous orbit, at a constant geocentric altitude of $\sim 830 \mathrm{~km}$. Since 1987, a series of DMSP spacecraft, named with the letter $\mathrm{F}$ and the flight number, have been sent to their designated orbits. The spacecraft carries a "Special SensorIons, Electrons and Scintillation" (SSIES) package to monitor the behavior of thermal plasma in the topside ionosphere. The $T_{e}$ data measured with the onboard Langmuir probe are available from the University of Texas, Dallas Web site (http://cindispace.utdallas.edu/DMSP/). On 3 October 2005 the F15 satellite traveled from $1^{\circ} \mathrm{W}, 41^{\circ} \mathrm{S}$ at $\sim 08: 15 \mathrm{UT}$ to $3.6^{\circ} \mathrm{W}, 47^{\circ} \mathrm{S}$ at $\sim 08: 17 \mathrm{UT}$. A partial eclipse with eclipse magnitude (fraction of the Sun's diameter covered by the
Moon at maximum eclipse) of $\sim 0.76$ was occurring in the magnetically conjugate region at the same time and the time of maximum eclipse in this region was at 08:45 UT. On one day before or after the eclipse day, the F15 satellite still traveled almost the same region with only 3 degrees shift in longitudinal direction at the same local time, so the data on 2 and 4 October could be considered as the background level. This provides us with a unique opportunity to measure electron temperature disturbances at the conjugate point of the eclipse region. The corresponding spatial locations of the F15 satellite on 2, 3, and 4 October are plotted in the top panel of Fig. 1. The corresponding information of the electron temperature in this region is shown in the bottom panel of Fig. 1.

According to IGRF95 model, the magnetically conjugate point of the ionosonde station Grahamstown $\left(26.5^{\circ} \mathrm{E}\right.$, $33.3^{\circ} \mathrm{S}$ ) approximately locates at $\sim 13.3^{\circ} \mathrm{E}, 33.5^{\circ} \mathrm{N}$ where a partial eclipse with eclipse magnitude of $\sim 0.91$ occurred and the time of maximum eclipse was $\sim 09: 18$ UT. We get the ionospheric data of the Grahamstown station from SPIDR and these data have been validated manually. The data from Grahamstown will help us investigate the disturbances in ionospheric parameters $f o \mathrm{~F} 2$ and $h m \mathrm{~F} 2$ in the conjugate region. We plot the variations of $f o \mathrm{~F} 2$ and $h m \mathrm{~F} 2$ on 3 October 2005 in Fig. 2a and b. In addition, their monthly mean and standard deviation from around the same epoch are also shown in Fig. 2, which would serve to show how unusual the observed deviations are from normal day-to-day variability in the ionosphere.

During the 08:00-12:00 UT, the elevation angle of satellite PRN (pseudo random noise) 2 at the GPS station SUTH $\left(32.4^{\circ} \mathrm{S}, 20.8^{\circ} \mathrm{E}\right)$ is larger than 50 degrees. The vertical TEC data are obtained by assuming an ionospheric spherical shell at an altitude of $350 \mathrm{~km}$ and the pierced point (IPP) is at $\sim 21^{\circ} \mathrm{E}$ and $\sim 33^{\circ} \mathrm{S}$. The corresponding magnetically conjugate point locates at $\sim 9.1^{\circ} \mathrm{E}, 34.2^{\circ} \mathrm{N}$ where a partial eclipse occurred with eclipse magnitude of $\sim 0.96$ and the time of maximum eclipse was $\sim 09: 14$ UT. So the data from this station is chosen to investigate the TEC disturbance of the conjugate region. During 08:00-12:00 UT within three days before and after the eclipse day, the elevation angles of satellite PRN 2 are all larger than 50 degrees, so we consider the 7-day means as the background values. The variation of the TEC on 3 October and its 7-day mean and standard deviation are shown in Fig. 2c.

\section{Ionospheric model}

For this work we modeled the response of the ionosphere during this solar eclipse using the Theoretical Ionospheric Model of the Earth in Institute of Geology and Geophysics, Chinese Academy of Sciences (TIME-IGGCAS) (Yue et al., 2008). It solves the 2-D coupled equations of the mass continuity, momentum, and energy for three dominant ions $\mathrm{O}^{+}$, 
$\mathrm{H}^{+}$and $\mathrm{He}^{+}$. The model also calculates the values of concentrations of three minor ions $\mathrm{N}_{2}^{+}, \mathrm{O}_{2}^{+}$and $\mathrm{NO}^{+}$in the Eand $\mathrm{F}$ - region under the assumption of photochemical equilibrium. The neutral temperature and densities are taken from the NRLMSIS-00 model (Picone et al., 2002), and the NO concentration is calculated from an empirical model developed by Titheridge (1997). The neutral winds are supplied by the HWM-93 model (Hedin et al., 1996). The photoelectron heating effect is similar to that of Millward et al. (1996). At low altitudes (below $300 \mathrm{~km}$ ), the photoelectron heat is distributed locally. At higher altitudes (above $300 \mathrm{~km}$ ), the photoelectron heat comes from local and also from sources in the other hemisphere.

To model the eclipse effects, the spectrum of solar radiation has been multiplied by an eclipse factor $\mathrm{F}$; see Le et al. (2008a, b) for details. The eclipse factor $\mathrm{F}$ is directly proportional to the unmasked fraction of the area of the Sun's photosphere which has been calculated by a JavaScript Eclipse Calculator developed by Chris O'Byrne and Stephen McCann (http://www.chris. obyrne.com/Eclipses/calculator.html).

In this study, to model the eclipse effects on the ionosphere in both hemispheres during the 3 October 2005 solar eclipse and compare the measured results with the simulated results, two simulations are carried out at two planes: the first one for the comparison of $T_{e}$ with the field lines over the location of $2.5^{\circ} \mathrm{E}, 45^{\circ} \mathrm{S}$ where is the middle location of the DMSP F15 satellite travelling mentioned in Sect. 2; and the second one for the comparison of foF 2 , $h m \mathrm{~F} 2$ and TEC with the field lines over the location of $23^{\circ} \mathrm{E}, 33^{\circ} \mathrm{S}$ where is close to both the ionosonde station Grahamstown and the GPS station SUTH. The solar activity index is set as F10.7=80 and the magnetic activity index is set as $A_{p}=5$. In order to identify the ionospheric effects of the eclipse, two additional simulations excluding the eclipse shadow were run and the results are considered as the background level on the control day. The changes in $N m \mathrm{~F} 2, N_{e}$ (electron density), TEC, $h m \mathrm{~F} 2, T_{e}$, and $\Phi$ (plasma field-aligned flux) between the eclipse and noneclipse simulation are defined as $r N m \mathrm{~F} 2=N m \mathrm{~F} 2 \mathrm{e} / N m \mathrm{~F} 2 \mathrm{c}$, $r N_{e}=\mathrm{Nee} / \mathrm{Nec}, r \mathrm{TEC}=\mathrm{TECe} / \mathrm{TECc}, \Delta h m \mathrm{~F} 2=h m \mathrm{~F} 2 \mathrm{e}-h m \mathrm{~F} 2 \mathrm{c}$, $\Delta T_{e}=$ Tee - Tec, and $\Delta \Phi=\Phi \mathrm{e}-\Phi \mathrm{c}$, respectively. The subscripts e and c denote the eclipse day and the control day, respectively.

\section{Results}

The measured $T_{e}$ from the DMSP F15 satellite on the eclipse day and background days are shown in Fig. 1. The simulated $T_{e}$ on the eclipse day and control day are also plotted in Fig. 1. Both the measurements and simulations show that there is a large $T_{e}$ decrease $\left(\sim 600 \mathrm{~K}\right.$ for measured $T_{e}$ and $\sim 450 \mathrm{~K}$ for simulated $T_{e}$ ) in the conjugated region when the solar eclipse occurred in the Northern Hemisphere although
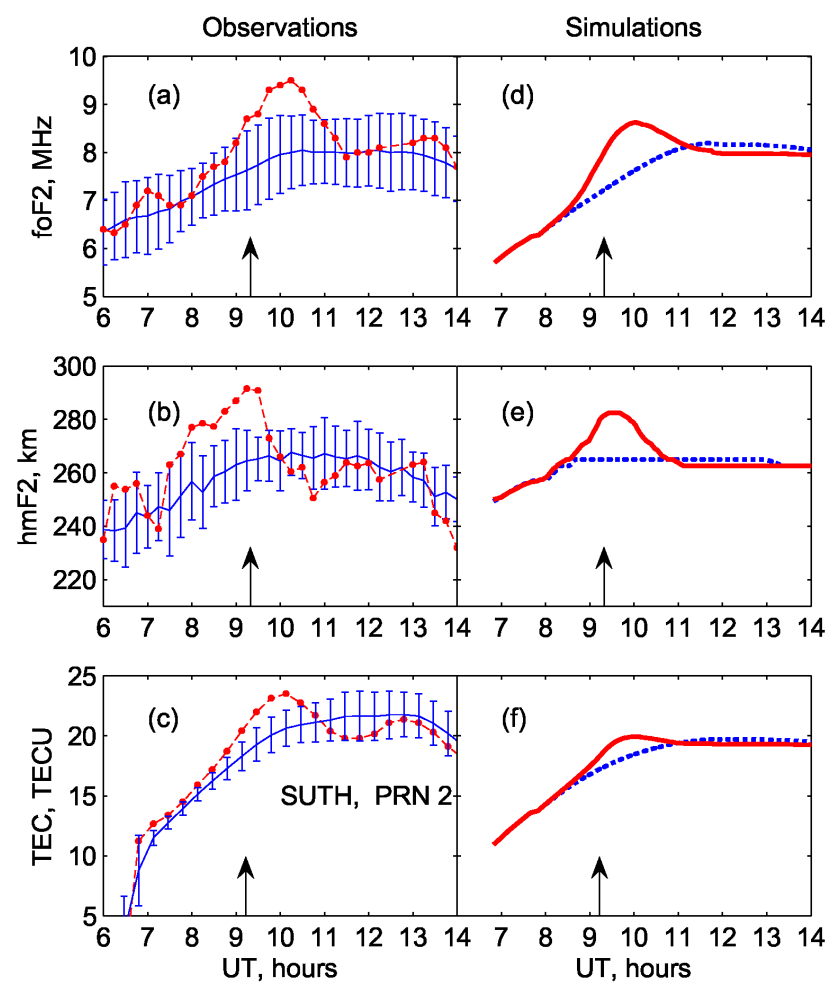

Fig. 2. Temporal variations of the measured $f o \mathrm{~F} 2$ (a) and the $h m \mathrm{~F} 2$ (b) at ionosonde station Grahamstown on 3 October 2005 (solid circle lines) and their monthly means (solid lines) and standard deviations. Temporal variations of the TEC (c) derived from GPS station SUTH (PRN 2) on 3 October 2005 (solid circle line) and its 7-day mean (solid line) and standard deviation. The corresponding simulated results of $f o \mathrm{~F} 2, h m \mathrm{~F} 2$, and TEC on the eclipse day (solid line) and on the control day (dotted line) are plotted in (d), (e), and (f), respectively. The error bars represent the standard deviations. In each panel, the maximum eclipse phase of the conjugate point is shown by a vertical arrow.

the simulated background value is larger by $350 \mathrm{~K}$ than the measured one.

The measured foF 2 and $h m \mathrm{~F} 2$ at Grahamstown, and their monthly mean and standard deviation are shown in Fig. 2a and $\mathrm{b}$. The corresponding simulated results of $f_{o} \mathrm{~F} 2$ and $h m \mathrm{~F} 2$ are also plotted in Fig. 2d and e. When looking at Fig. 2, one can see that there are two clear events from $\sim 06: 00 \mathrm{UT}$ to 11:00 UT. The first event starting at $\sim 06: 00 \mathrm{UT}$ shows an uplift of $h m \mathrm{~F} 2$ with a simultaneous swelling of the F2 layer and an enhancement of the $f o \mathrm{~F} 2$ half an hour later. The second event starting at $\sim 07: 15$ UT shows a similar behavior but has longer duration than the previous one. Furthermore, in this event there is like a second impulse starting by about 08:30 UT. Both the first event and the first impulse of the second event are far enough in time from the eclipse time and could not be considered to be induced by the eclipse. For the second impulse, one can see that the starting time of the response of both $f_{o} \mathrm{~F} 2$ and $h m \mathrm{~F} 2$ are practically 


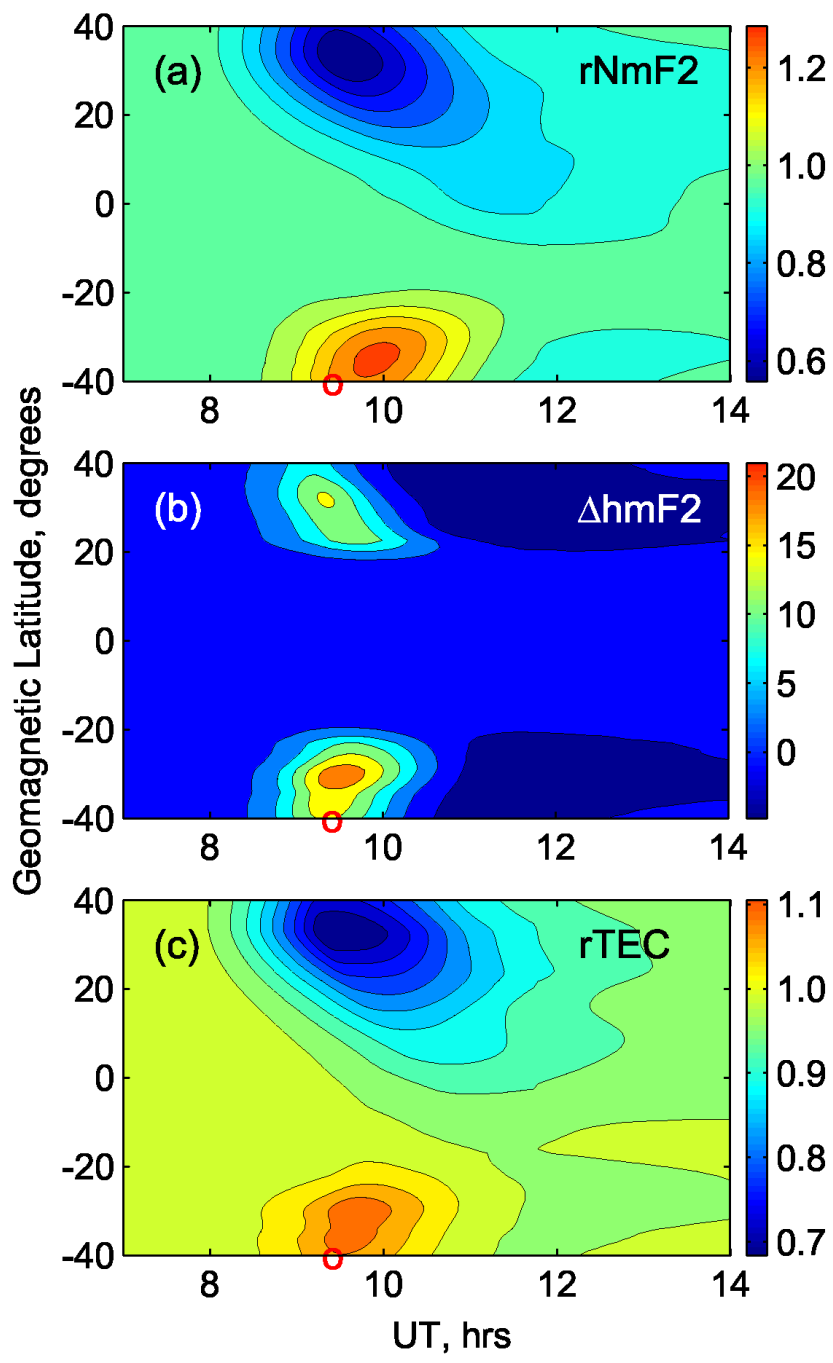

Fig. 3. The simulated ionospheric responses to the solar eclipse during 07:00-14:00 UT from $40^{\circ} \mathrm{S}$ to $40^{\circ} \mathrm{N}$. (a) for $r N m \mathrm{~F} 2$, (b) for $\Delta h m \mathrm{~F} 2(\mathrm{~km})$, and (c) for $r$ TEC. The circles on $\mathrm{x}$-axis indicate the totality of solar eclipse.

simultaneous (at about 08:30 UT); there is a peak uplift in $h m \mathrm{~F} 2$ of about $15 \mathrm{~km}$ at $\sim 09: 30 \mathrm{UT}$ and a peak increase in $f o \mathrm{~F} 2$ of about $1.3 \mathrm{MHz}$ at half hour later $\sim 10: 00 \mathrm{UT}$. These results are pretty much consistent with the simulated results: a peak $h m \mathrm{~F} 2$ increase of $\sim 18 \mathrm{~km}$ at 09:25 UT and a peak foF2 increase of $\sim 0.98 \mathrm{MHz}$ at $\sim 10: 00 \mathrm{UT}$ and the starting time of the modeled response occurs simultaneously for both $h m \mathrm{~F} 2$ and $f o \mathrm{~F} 2$ at $\sim 08: 30 \mathrm{UT}$, as shown in Fig. $2 \mathrm{~d}$ and e. Figure 2c shows the measured TEC from the GPS station SUTH and the simulated TEC. From Fig. 2c, one can see that during the eclipse the measured TEC is larger than the background level with the largest increase of $\sim 3$ TECU (a TEC unit is $10^{16}$ electrons $/ \mathrm{m}^{2}$ ) at $\sim 10: 00 \mathrm{UT}$, corresponding to $15 \%$ of the background value. Figure $2 \mathrm{f}$ shows similar increase in the simulated TEC but with smaller amplitude of $\sim 1.68$ TECU (9.4\% of the background level).

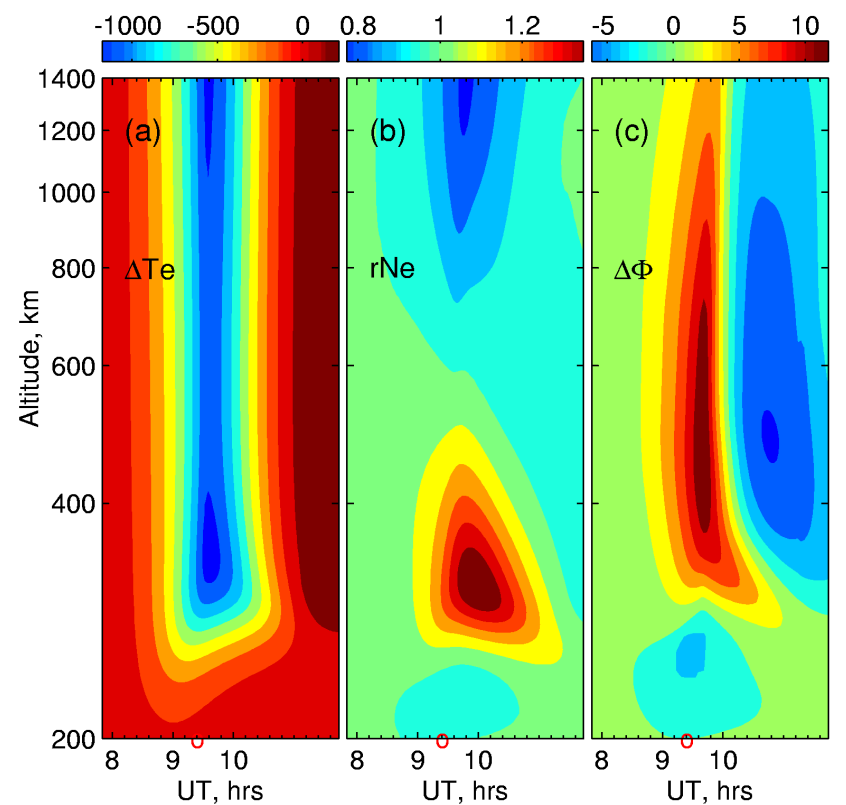

Fig. 4. The simulated ionospheric disturbances during 07:0014:00 UT in $33^{\circ} \mathrm{S}$. (a) for $\Delta T_{e}(\mathrm{~K})$, (b) for $r N_{e}$, and (c) for $\Delta \Phi$ $\left(10^{12} \mathrm{~m}^{-2} \mathrm{~s}^{-1}\right)$. The circles on $\mathrm{x}$-axis indicate the totality of solar eclipse of the conjugate point $\left(33^{\circ} \mathrm{N}\right)$. In Fig. $4 \mathrm{c}$, positive (negative) denotes downward (upward) diffusion.

The more detailed temporal and spatial variations in the simulated results of the second simulation are shown in Figs. 3 and 4. In Fig. 3, $r N m \mathrm{~F} 2, \Delta h m \mathrm{~F} 2$, and $r$ TEC are plotted as a function of latitude and time. Figure 3 shows that there are obvious eclipse effects in the eclipse region, such as the rapid decrease with the peak decrease of $\sim 43 \%$ in $N m \mathrm{~F} 2$ at 09:15 UT, the uplift in $h m \mathrm{~F} 2$ with peak increase of $\sim 15 \mathrm{~km}$ at $\sim 09: 20 \mathrm{UT}$, and the large decrease of $\sim 31 \%$ in TEC in the eclipse region at $\sim 09: 25$ UT. These results are in agreement with the previous measurements for the same eclipse event reported by Jakowski et al. (2008). For the ionospheric disturbances in the conjugate hemispheres, one can see from Fig. 3 that there is a peak increase of $29 \%$ in $N m \mathrm{~F} 2$ at 09:45 UT, as well as a peak increase of $\sim 11 \%$ in TEC at $\sim 09: 40 \mathrm{UT}$; and the $h m \mathrm{~F} 2$ gets some raise with peak increase of $\sim 22 \mathrm{~km}$ at $\sim 09: 30$ UT. Comparing the time of the largest responses in the eclipse region to that in its conjugate region, one also can find that the ionospheric responses in the conjugate region are later than those in the eclipse region.

From Fig. 3, we can find out that the largest disturbance place locates at $\sim 33^{\circ} \mathrm{S}$. To better illustrate the change at the conjugate point of the eclipse region, we plotted the change in $N_{e}, T_{e}$, and $\Phi$ (plasma flux) at $33^{\circ} \mathrm{S}$ as a function of altitude and time in Fig. 4. Figure 4a shows there is an overall decrease in electron temperature throughout the entire height range with a greatest drop of around $1250 \mathrm{~K}$ at $\sim 305 \mathrm{~km}$ altitude at $\sim 09: 24 \mathrm{UT}$. These changes in $T_{e}$ alter the plasma scale height, contracting the F2 region and 
forcing plasma at high altitudes to diffuse downward and plasma at low altitudes to diffuse upward. Figure $4 \mathrm{c}$ shows these plasma field-aligned fluxes: there are downward diffusions at altitudes $\sim 300 \mathrm{~km}$ above and upward diffusions at altitudes $220-290 \mathrm{~km}$. These plasma diffusions subsequently alter plasma altitude distribution. Figure $4 \mathrm{~b}$ illustrates the changes in $N_{e}$. There is a large decrease at altitudes of $600 \mathrm{~km}$ and above with the largest amplitude of $\sim 23 \%$ at around $1300 \mathrm{~km}$, a remarkable increase at altitudes of 250$600 \mathrm{~km}$ with the peak amplitude of nearly $40 \%$ at $\sim 310 \mathrm{~km}$, as well as a smaller decrease at $250 \mathrm{~km}$ and below with peak amplitude no more than $10 \%$. These plasma diffusions would shift $h m \mathrm{~F} 2$ to higher altitudes and enhance $N m \mathrm{~F} 2$ as well as TEC (as shown in Fig. 3).

\section{Discussion}

As it is well known that at lower altitudes, most of the photoelectron heat is distributed locally; while at higher altitudes, the energetic electrons are able to propagate along the magnetic field lines to heat the gas in the conjugate hemisphere. That is, at higher altitudes (above $\sim 300 \mathrm{~km}$ ), the photoelectron heat not only comes from local hemisphere but also from the conjugate hemisphere. Some studies have shown presunrise plasma temperature enhancements was contributed to by the photoelectron heating from the conjugate sunlit region (Evans, 1973; Peterson et al., 1977; Chao et al., 2003, Zhang et al., 2004). During a solar eclipse, photoelectrons in the eclipse region are reduced largely at totality, then in its conjugate region the inflow photoelectron flux from the eclipse region will decrease a lot, which results in a large decrease in electron temperature in this region.

As mentioned above, for a place ( $300 \mathrm{~km}$ and above) in the conjugate hemisphere the photoelectron heat can be divided into two parts: one from the local hemisphere (non eclipse hemisphere) and the other from the conjugate hemisphere (eclipse hemisphere). If the contribution from the conjugate hemisphere is greater on the control day, the loss of photoelectron heat will be greater when a solar eclipse occurred in the conjugate hemisphere, which will result in the greater disturbance in this place. Otherwise there would be a smaller disturbance. According to an empirical photoelectron flux model (Millward et al., 1996), contributions from these two parts are determined by the ratio of plasma concentration in the local hemisphere to the conjugate: the ratio the larger, the greater the contribution from the conjugate hemisphere is, because the larger ratio means relatively less plasma concentration in the conjugate hemisphere which causes more inflow photoelectrons from the conjugate hemisphere due to fewer photoelectrons being absorbed there. In our simulation, the ratio of the TEC at $33^{\circ} \mathrm{S}$ to that at $33^{\circ} \mathrm{N}$ reaches 1.75 , which results in an overall decrease in photoelectron heating throughout the entire height range at $33^{\circ} \mathrm{S}$. The peak decrease amplitude reaches around 32\%-55\% at altitudes from $300 \mathrm{~km}$ to $3000 \mathrm{~km}$. It is the large loss of photoelectron heating rate that causes a large decrease in plasma temperature and subsequent disturbances in the ionosphere. In addition, our simulations show that if this ratio is less than 1.0 there would be a much smaller disturbance in the conjugate region (with no more than $15 \%$ increase in $N m \mathrm{~F} 2$ ).

\section{Summary}

This paper presents an initial result on the ionospheric disturbance in the conjugate hemisphere during the total eclipse on 3 October. Observations from the DMSP F15 satellite show a great drop in electron temperature. The ionosonde data at Grahamstown show a marked increase in $N m \mathrm{~F} 2$ and a rising $h m \mathrm{~F} 2$. The GPS TEC from SUTH also presents a distinct enhancement in TEC. Then we modeled the ionospheric behavior during this eclipse using a mid- and lowlatitude ionospheric model. The simulations reproduced all the observed results well. Simulations suggest that during this solar eclipse, the decrease in plasma temperature altered plasma scale height and consequently resulted in enhanced $N m \mathrm{~F} 2$ and TEC and $h m \mathrm{~F} 2$ rising to higher altitudes. Furthermore, simulations show the decrease in plasma temperature was caused by the large depression of inflow photoelectron flux coming from the eclipse region.

Acknowledgements. The authors also express their special thanks to the Center for Space Sciences at University of Texas at Dallas and the US Air Force for providing the DMSP thermal plasma data. The authors also thank the Space Physics Interactive Data Resource for supplying the ionospheric data. This research was supported by National Natural Science Foundation of China (40725014, 40674090, and 40636032) and National Important Basic Research Project (2006CB806306).

Topical Editor M. Pinnock thanks two anonymous referees for their help in evaluationg this paper.

\section{References}

Afraimovich, E. L., Palamartchouk, K. S., Perevalova, N. P., Chemukhov, V. V., Lukhnev, A. V., and Zalutsky, V. T.: Ionospheric effects of the solar eclipse of March 9, 1997, as deduced from GPS data, Geophys. Res. Lett., 25(4), 465-468, 1998.

Boitman, O. N., Kalikhman, A. D., and Tashchilin, A. V.: The midlatitude ionosphere during the total solar eclipse of March 9, 1997, J. Geophys. Res., 104(A12), 28197-28206, 1999.

Chao, C. K., Su, S.-Y., and Yeh, H. C.: Presunrise ion temperature enhancement observed at $600 \mathrm{~km} \mathrm{low}$ and mid-latitude ionosphere, Geophys. Res. Lett., 30(4), 1187, doi:10.1029/2002GL016268, 2003.

Davis, C. J., Lockwood, M., Bell, S. A., Smith, J. A., and Clarke, E. M.: Ionospheric measurements of relative coronal brightness during the total solar eclipses of 11 August, 1999 and 9 July, 1945, Ann. Geophys., 18, 182-190, 2000, http://www.ann-geophys.net/18/182/2000/. 
Evans, J. V.: Seasonal and sunspot cycle variation of $\mathrm{F}$ region electron temperatures and protonospheric heat flux, J. Geophys. Res., 78, 2344-2349, 1973.

Hedin, A. E., Fleming, E. L., Manson, A. H., et al.: Empirical wind model for the upper, middle and lower atmosphere, J. Atmos. Terr. Phys., 58, 1421-1447, 1996.

Jakowski, N., Stankov, S. M., Wilken, V., et al.: Ionospheric behavior over Europe during the solar eclipse of 3 October 2005, J. Atmos. Terr. Sol.-Phys., 70, 836-853, 2008.

Le, H., Liu, L., Yue, X., and Wan, W.: The ionospheric responses to the 11 August 1999 solar eclipse: observations and modeling, Ann. Geophys., 26, 107-116, 2008a, http://www.ann-geophys.net/26/107/2008/.

Le, H., Liu, L., Yue, X., and Wan, W.: The midlatitude F2 layer during solar eclipses: Observations and modeling, J. Geophys. Res., 113, A08309, doi:10.1029/2007JA013012, 2008b.

Millward, G. H., Moett, R. J., Quegan, S., and Fuller-Rowell, T. J.: A Coupled Thermosphere-Ionosphere-Plasmasphere Model (CTIP), in: Solar Terrestrial Energy Program: Handbook of Ionospheric Models, edited by: Schunk, R. W., pp. 239-279, Utah State Univ., Logan, 1996.

Müller-Wodarg, I. C. F., Aylward, A. D., and Lockwood, M.: Effects of a Mid-Latitude Solar Eclipse on the Thermosphere and Ionosphere - A Modelling Study, Geophys. Res. Lett., 25(20), 3787-3790, 1998.

Peterson, W. K., Doering, J. P., Potemra, T. A., McEntire, R. W., and Bostrom, C. O.: Conjugate Photoelectron Fluxes Observed on Atmosphere Explorer C, Geophys. Res. Lett., 4(3), 109-112, 1977.
Picone, J. M., Hedin, A. E., Drob, D. P., and Aikin, A. C.: NRLMSISE-00 empirical model of the atmosphere: statistical comparisons and scienti5c issues, J. Geophys. Res., 107(A12), 1468, doi:10.1029/2002JA009430, 2002.

Salah, J. E., Oliver, W. L., Foster, J. C., and Holt, J. M.: Observations of the May 30, 1984, Annular Solar Eclipse at Millstone Hill, J. Geophys. Res., 91(A2), 1651-1660, 1986.

Stubbe, P.: The F-region during an eclipse - A theoretical study, J. Geophys. Res., 32, 1109-1116. 1970.

Titheridge, J. E.: Model results for the ionospheric E region: solar and seasonal changes, Ann. Geophys., 15, 63-78, 1997, http://www.ann-geophys.net/15/63/1997/.

Tsai, H. F. and Liu, J. Y.: Ionospheric total electron content response to solar eclipses, J. Geophys. Res., 104(A6), 1265712668, 1999.

Yue, X., Wan, W., Liu, L., Le, H., Chen, Y., and Yu, T.: Development of a middle and low latitude theoretical ionospheric model and an observation system data assimilation experiment, Chinese Sci. Bull, 53(1), 94-101, 2008.

Zhang, S.-R., Holt, J. M., Zalucha, A. M., and Amory-Mazaudier, C.: Midlatitude ionospheric plasma temperature climatology and empirical model based on Saint Santin incoherent scatter radar data from 1966 to 1987, J. Geophys. Res., 109, A11311, doi:10.1029/2004JA010709, 2004. 